\title{
GENDER COMPARISONS IN ANAEROBIC POWER AND ANAEROBIC CAPACITY TESTS
}

\author{
P. J. MAUD, PhD, FACSM* and B. B. SHULTZ, PhD** \\ *Department of Physical Education and Leisure Management, Columbus College, Columbus, Georgia 31993 \\ **Department of Physical Education, University of Utah, Salt Lake City, Utah 84112
}

\section{ABSTRACT}

The purpose of the study was to compare anaerobic power and anaerobic capacity test scores between young active men and women. Three performance measures of anaerobic power and two of anaerobic capacity were administered to a sample comprising 52 male and 50 female college students ( $\bar{x}$ age $=21.4 \mathrm{yrs}$ ). Results indicated significant differences between men and women in body height, weight and per cent fat, in fat free mass (FFM), anaerobic power, and anaerobic capacity when recorded as gross work completed and relative to body weight. However, these differences are reduced when data is adjusted for body weight and further reduced when corrected for FFM. The study found no significant differences between men and women in either anaerobic power or anaerobic capacity when values were given relative to FFM.

Key words: Anaerobic power, Anaerobic capacity, Gender comparison

\section{INTRODUCTION}

There has been considerable interest shown recently in the differing physiological responses to physical activity of the female as compared to the male. Recent reviews of the literature concerning the nature and causes of these differences have been presented, for example, by Wells and Plowman (1983), Pate and Kreska (1984), and Drinkwater (1984). Many different parameters have been studied, but particularly those related to body size, body composition, muscular strength, and cardiorespiratory endurance.

Investigation of possible differences in anaerobic power and anaerobic capacity have received far less attention. Limited data comparing the adult female with the adult male is, however, available for some anaerobic tests. For example, differences in response to the Wingate $5 \mathrm{~s}$ and $30 \mathrm{~s}$ tests have been reported by Ben Ari et al (1978) and by Murphy et al (1984) for adult males and females and by Gleim et al (1984) for male and female ballet dancers. Fox and Mathews (1974) also give age adjusted norms for both sexes for the Kalamen adaptation of the Margaria test. Further, a relatively comprehensive study by DeBruynPrevost and Sturbois (1984) compared anaerobic capacities between male and female physical education students.

The purpose of the current investigation was to document anaerobic power and anaerobic capacity work test scores of, and differences between, young active female and male subjects with test scores reported as gross measures and corrected for body weight and fat free mass.

\section{METHODS}

Subjects for the study consisted of 52 males and 50 female volunteer college students, age range 18.3 to 28.0 years. At the time of testing all were considered to be physically active as defined by their participating in strenuous physical exercise on a minimum of three days per week for a period of at least six woeks prior to the tests.

Tests were administered on two separate days with a minimum of three days and a maximum of five days between tests. Testing sequence was varied in order to negate learning and/or fatigue effects.

Anthropometric data collected included standing body height recorded to the nearest $1 \mathrm{~cm}$, body weight recorded to the nearest $0.1 \mathrm{~kg}$ and skinfold fat thickness to the nearest $1 \mathrm{~mm}$. Skinfold fat was measured on the right side of the body by use of Lange skinfold calipers at the thigh, abdomen and chest for men and the thigh, suprailiac and triceps for women. Body density was determined from skinfold thicknesses by use of generalised equations for men (Jackson and Pollock, 1978) and for women (Jackson et al, 1980). Rationalisation for the use of generalised, as opposed to population specific, equations is discussed in detail by Jackson and Pollock (1982). Per cent fat was derived from body density by use of the formula of Siri (1961). Fat free mass (FFM) was calculated from the body weight and per cent body fat data.

Two anaerobic capacity tests, designed to measure work output per unit of time, were administered on separate days. Both utilised a Monark bicycle ergometer as the exercise modality with pedal revolutions, to the nearest quarter revolution completed, recorded on a chart recorder in response to an electronically triggered microswitch. Warm up procedures for both tests were identical.

One test utilised the protocol of Katch et al (1977) where subjects completed an all-out $\mathbf{4 0}$ second pedalling task against a frictional resistance of $6 \mathrm{~kg}$ force for men and $5 \mathrm{~kg}$ for women. Work after $40 \mathrm{~s}$ was recorded as gross work completed (kgm.min $\left.{ }^{-1}\right)$, relative to body weight $\left(\mathrm{kgm} \cdot \mathrm{kg}^{-1} \mathrm{~min}^{-1}\right)$ and relative to fat free mass (kgm.kg FFM-1 $\min ^{-1}$ ). For comparison purposes anaerobic capacity test data was also converted from kgm.min ${ }^{-1}$ to Watts. In the other test the Wingate protocol (Bar-Or et al, 1980) was used where the subject pedals all-out for 30 seconds against a frictional resistance adjusted relative to body weight, $0.075 \mathrm{~kg}$ force per $\mathrm{kg}$ body weight. Thirty second work was again recorded as gross values and relative to body weight and fat free mass.

Anaerobic power, measured in $\mathrm{kgm} . \mathrm{s}^{-1}$, was determined utilising three different test protocols. The Lewis equation, as described by Fox and Matthews (1974), was used to derive anaerobic power from body weight and vertical jump height, where the best of three trials was recorded to the nearest $1 \mathrm{~mm}$. The Margaria-Kalamen stair run test (Fox and Mathews, 1974) derived anaerobic power from body weight, vertical distance travelled and task time completion. The vertical distance travelled was 1.1 metres and the best of six trials recorded to the nearest one hundredth of a second was used for task time completion. Data for the third test was obtained from the Wingate Anaerobic Capacity Test (Bar-Or et al, 1980) with anaerobic power output being defined as the highest mechanical power output for any one, five second period of exercise.

In order to determine whether or not differences existed between male and female test data a one-way MANOVA, using Wilks' lambda as the significance test, was employed. A discriminant analysis was conducted as the follow-up procedure (Bray and Maxwell, 1982). Additionally, to determine the significance of differences between men and women for each variable alone, univariate $F$ 's were reported.

\section{RESULTS}

Descriptive statistics, percentage differences between male and female test scores, and univariate $F$ ratios with significance level for each test, are reported for physical characteristics, anaerobic power, and anaerobic capacity in Tables I, II, and III respectively.

TABLEI

Deceriptive statistics, per cent difference, and univariate $F$ value for physical characteriotics

\begin{tabular}{lrrrrr}
\hline & $\begin{array}{c}\text { Men* } \\
(n=52)\end{array}$ & $\begin{array}{c}\text { Women* } \\
(n=50)\end{array}$ & $\begin{array}{c}\% \\
\text { Difference }\end{array}$ & F & $P$ \\
\hline Age (yr) & $21.6 \pm 1.8$ & $21.2 \pm 2.0$ & 1.9 & 1.1 & .296 \\
Height (cm) & $174.4 \pm 9.3$ & $167.6 \pm 6.5$ & 4.1 & 54.4 & .000 \\
Weight (kg) & $77.3 \pm 10.1$ & $59.6 \pm 8.0$ & 29.7 & 95.2 & .000 \\
Body Fat (\%) & $10.6 \pm 4.0$ & $19.7 \pm 4.8$ & 46.2 & 107.7 & .000 \\
Fat Free Mass (kg) & $69.0 \pm 7.9$ & $47.5 \pm 5.0$ & 45.3 & 265.0 & .000 \\
\hline
\end{tabular}

"Values are reported as means \pm standard deviation 
TABLE U

Descriptive statistics, per cent difference, and univariate F value for anaerobic power test scores

\begin{tabular}{|c|c|c|c|c|c|}
\hline & $\begin{array}{c}\text { Men* } \\
(n=52)\end{array}$ & $\begin{array}{l}\text { Women* } \\
(n=50)\end{array}$ & $\begin{array}{c}\% \\
\text { Difference }\end{array}$ & $\boldsymbol{F}$ & $\boldsymbol{P}$ \\
\hline Vertical Jump Height (cm) & $53.0 \pm 6.7$ & $36.4 \pm 4.8$ & 45.6 & 205.9 & .000 \\
\hline Vertical Jump (cm. $\mathrm{kg}^{-1}$ ) & $.70 \pm \quad .12$ & $.62 \pm \quad .13$ & 12.9 & 8.7 & .004 \\
\hline Vertical Jump (cm.kg FFM-1) & $.78 \pm \quad .12$ & $.78 \pm .14$ & 0.0 & 0.0 & .988 \\
\hline Lewis Test $\left(\mathrm{kgm}_{.} \mathrm{s}^{-1}\right)$ & $123.5 \pm 19.0$ & $79.2 \pm 10.5$ & 55.9 & 211.0 & .000 \\
\hline Margaria-Kalamen Test (kgm.s ${ }^{-1}$ ) & $168.1 \pm 26.9$ & $90.0 \pm 14.4$ & 86.8 & 329.8 & .000 \\
\hline Wingate 5 Sec Test (kgm.s $\left.{ }^{-1}\right)$ & $72.6 \pm 9.1$ & $48.1 \pm 8.1$ & 50.9 & 203.8 & .000 \\
\hline Wingate 5 Sec Test (kgm. $\left.\mathrm{kg}^{-1} \mathrm{~s}^{-1}\right)$ & $0.95 \pm 0.13$ & $0.81 \pm 0.11$ & 17.3 & 32.5 & .000 \\
\hline Wingate 5 Sec Test (kgm.kg FFM ${ }^{-1} \mathrm{~s}^{-1}$ ) & $1.06 \pm 0.13$ & $1.01 \pm 0.14$ & 5.0 & 2.9 & .092 \\
\hline
\end{tabular}

*Values are reported as means \pm standard deviation

TABLE III

Descriptive statistics, per cent difference, and univariate $F$ value for anaerobic capacity test scores

\begin{tabular}{|c|c|c|c|c|c|c|c|}
\hline \multirow{3}{*}{$\begin{array}{l}\text { Wingate } 30 \text { Sec Test (kgm.min }{ }^{-1} \text { ) } \\
\text { (Watts) }\end{array}$} & \multicolumn{2}{|c|}{$\begin{array}{c}\text { Men* } \\
(n=52)\end{array}$} & \multicolumn{2}{|c|}{$\begin{array}{l}\text { Women* } \\
(n=50)\end{array}$} & \multirow[t]{2}{*}{$\begin{array}{c}\% \\
\text { Difference }\end{array}$} & \multirow[t]{2}{*}{$\boldsymbol{F}$} & \multirow[t]{2}{*}{$P$} \\
\hline & 3414 & \pm 391 & $2307 \pm$ & 348 & & & \\
\hline & 562.7 & 66.5 & 380.8 & 56.4 & 48.0 & 227.4 & .000 \\
\hline $\begin{array}{r}\text { Wingate } 30 \text { Sec Test (kgm.kg }{ }^{-1} \mathrm{~min}^{-1} \text { ) } \\
\left.\text { (Watts.kg FFM }{ }^{-1}\right)\end{array}$ & $\begin{array}{c}44.6 \pm \\
7.28\end{array}$ & $\begin{array}{c}5.4 \\
.88\end{array}$ & $\begin{array}{c}38.7 \\
6.35\end{array}$ & $\begin{array}{r}4.1 \\
.73\end{array}$ & 15.2 & 37.7 & .000 \\
\hline $\begin{array}{r}\text { Wingate } 30 \text { Sec Test (kgm.kg FFM-1 } \min ^{-1} \text { ) } \\
\text { (Watts.kg FFM }{ }^{-1} \text { ) }\end{array}$ & $\begin{array}{l}49.6 \pm \\
8.11\end{array}$ & $\begin{array}{c}5.0 \\
.82\end{array}$ & $\begin{array}{l}48.4 \pm \\
7.96\end{array}$ & $\begin{array}{c}4.8 \\
.88\end{array}$ & 2.5 & 1.6 & .205 \\
\hline $\begin{array}{l}\text { Katch } 40 \text { Sec Test (kgm.min }{ }^{-1} \text { ) } \\
\text { (Watts) }\end{array}$ & $\underset{359.9}{3269} \pm$ & $\begin{array}{r} \pm 347 \\
62.1\end{array}$ & $\underset{364.8}{2231} \pm$ & $\begin{array}{l}337 \\
50.6\end{array}$ & 46.5 & 234.6 & .000 \\
\hline $\begin{array}{r}\text { Katch } 40 \text { Sec Test }\left(\mathrm{kgm}^{\mathrm{kgg}} \mathbf{~}^{-1} \mathrm{~min}^{-1}\right) \\
\left.\text { (Watts. } \mathrm{kg}^{-1}\right)\end{array}$ & $\begin{array}{l}42.6 \pm \\
6.90\end{array}$ & $\begin{array}{r}4.4 \\
.76\end{array}$ & $\begin{array}{c}37.7 \pm \\
6.13\end{array}$ & $\begin{array}{r}5.4 \\
.81\end{array}$ & 13.0 & 26.0 & .000 \\
\hline $\begin{array}{r}\text { Katch } 40 \text { Sec Test (kgm.kg FFM }{ }^{-1} \mathrm{~min}^{-1} \text { ) } \\
\text { (Watts.kg FFM }{ }^{-1} \text { ) }\end{array}$ & $\begin{array}{c}47.7 \pm \\
7.65\end{array}$ & $\begin{array}{c}4.2 \\
.73\end{array}$ & $\begin{array}{c}47.0 \pm \\
7.69\end{array}$ & $\begin{array}{c}5.9 \\
.89\end{array}$ & 1.5 & 0.3 & .566 \\
\hline
\end{tabular}

*Values are reported as means \pm standard deviation

One-way MANOVA analysis resulted in a significant approximate $F_{(1586)}=\mathbf{4 3 . 8 9}$ with $p<.001$. As can be seen from inspection of Tables I, II, and III, significant differences existed between male and female scores for all variables except for age, and the vertical jump, Wingate $5 \mathrm{~s}$, Wingate $20 \mathrm{~s}$ and Katch $\mathbf{4 0} \mathrm{s}$ tests when reported relative to fat free mass. Although repeated tests on the same subjects increase the probability of a Type I error, it should be noted that in all cases the level of significance was less than .001.

Standardised discriminant coefficients indicate the unique contribution of a variable to the discriminant function. Those statistically significant discriminants, using Wilks' lambda as the selection criteria, are shown in Table IV. The Margaria anaerobic power test with a coefficient of .776 and per cent body fat with a coefficient of -.604 were the primary discriminators. These two were more than three times as important as the other two discriminators, the Wingate $5 \mathrm{~s}$ test reported as an absolute score and vertical jump height.

Since several of the anerobic power and capacity tests were highly correlated with each other and thus shared variance, the relative importance of some variables, as measured by standardised discriminant coefficients, may have been masked. The relationship of each variable to the discriminant function is measured by the structure coefficients. These are bivariate correlations between the predictor variable and the discriminant function without accounting for the correlation of other predictor variables. They are important for interpreting and naming the discriminant function. These structure coefficients are
TABLE IV

Coefficients for discriminant analysis follow-up test

\begin{tabular}{|c|c|c|}
\hline Variable & $\begin{array}{l}\text { Standardised } \\
\text { Discriminant } \\
\text { Coefficients* }\end{array}$ & $\begin{array}{l}\text { Structure } \\
\text { Coefficient }\end{array}$ \\
\hline Per cent Body Fat $(\%)$ & -0.604 & -0.396 \\
\hline Fat Free Mass (kg) & & 0.604 \\
\hline Vertical Jump height (cm) & 0.192 & 0.547 \\
\hline Vertical Jump height (cm.kg FFM-1) & & 0.048 \\
\hline Lewis Test (kgm.s $\mathrm{s}^{-1}$ ) & & 0.562 \\
\hline Margaria-Kalamen Test (kgm.s ${ }^{-1}$ ) & 0.776 & 0.693 \\
\hline Wingate 5 Sec Test (kgm. s $^{-1}$ ) & 0.217 & 0.545 \\
\hline Wingate 5 Sec Test (kgm.kg FFM ${ }^{-1} \mathrm{~min}^{-1}$ ) & & 0.111 \\
\hline Wingate 30 Sec Test (kgm.min ${ }^{-1}$ ) & & 0.596 \\
\hline Wingate 30 Sec Test (kgm.kg FFM-1 $\mathrm{min}^{-1}$ ) & & 0.094 \\
\hline Katch 40 Sec Test (kgm.min ${ }^{-1}$ ) & & 0.605 \\
\hline Katch 40 Sec Test (kgm.kg FFM-1 $\mathrm{min}^{-1}$ ) & & 0.096 \\
\hline
\end{tabular}

*Only statistically significant discriminators using Wilks' lambda as the selection criterion are reported.

presented in Table IV. In addition to the variables identified by the standardised discriminant coefficients it can be seen that the Wingate $5 \mathrm{~s}$, Wingate $30 \mathrm{~s}$, and Katch $40 \mathrm{~s}$ tests when uncorrected for body weight or fat free mass have relatively high structure coefficients. Since the inter-test correlations for these variables were all above $r=.70$, the unique contribution of any one test was diminished because of their shared variance. 


\section{DISCUSSION}

Primary interest in fitness research has traditionally centred upon cardiorespiratory endurance. A comparatively recent development has been an awareness of the importance of the other two primary energy systems, splitting of the high energy phosphate bonds (ATP and CP) as represented by anaerobic power, and anaerobic glycolysis represented by anaerobic capacity. Physiological indices of anaerobic metabolism such as muscle glycogen, ATP, CP and lactate levels involve complex, expensive, sophisticated and invasive techniques. For these reasons a number of relatively simple performance tests have been devised to reflect anaerobic function. This study investigated differences between young adult female and male subjects in response to some of these anaerobic tests.

With regards to physical characteristics the two groups were significantly different in body height, body weight, per cent body fat and fat free mass but were similar with regards to age, as indicated by no significant difference being found between the two groups. By selection definition they were equated relative to minimum activity levels but, as no detailed data was obtained relative to exercise intensity, duration and frequency, training programmes may have differed between groups. As has been observed by Zwiren, Cureton and Hutchinson (1983) this is one of the possible limitations to studies of this nature.

No statistically significant differences were found between men and women, providing that results were expressed relative to FFM, in either the three anaerobic capacity tests or in anaerobic power as determined by the Wingate $5 \mathrm{~s}$ test. Significant differences were found for all other anaerobic tests whether reported as absolute values or relative to body weight. Percentage differences were, however, found to be reduced when absolute values were corrected for body weight.

Other studies using the Wingate protocol for anaerobic power and capacity tests report similar findings. Ben Ari et al (1978) and Murphy et al (1984) report significant differences of $30.5 \%$ and $66.5 \%$ respectively in absolute anaerobic capacity scores compared to $48 \%$ in this study. Both note a decrease in differences when reporting relative to body weight while Murphy et al (1984) reported further decrease when scores were corrected for FFM.

In a study utilising a different anaerobic capacity test protocol, DeBruyn-Prevost and Sturbois (1984) found differences between 74 male and 70 female physical education students in anaerobic capacities when recorded as gross measures. There were no statitically significant differences between the two sexes when results were compared relative to body weight. However, in this study it should be noted that work loads for the two sexes were not equated as the women worked at lower work loads than that for the men.

Ben Ari et al (1978), Murphy et al (1984) and Gleim et al (1984) all show significant differences in absolute anaerobic power for the Wingate 5 s test. In the latter study, when data was adjusted for FFM, the difference of $8.5 \%$ between men and women was not significant.

Significant differences were found in anaerobic power between the sexes when using both the Margaria-Kalamen and Lewis protocols. Due to the fact that body weight is an integral part of the power computation it is difficult to report results relative to either body weight or FFM and, as with the other tests, significant differences between men and women would be expected when scores are reported in absolute terms.
The two most significant discriminants that differentiated between men and women were per cent body fat and the Margaria-Kalamen test score. Per cent body fat is a physical characteristic and as women typically have $10 \%$ higher values than men they will always be at a disadvantage. With regards to the Margaria-Kalamen test score it is of interest to note that Katch and Weltman (1979) declined to use the Margaria test to determine anaerobic power due to its high correlation $(r>0.90)$ to body weight and poor correlation to other external anaerobic work estimates. In this study the correlation between the Margaria-Kalamen test and body weight was $r=.88$.

The other two discriminants were vertical jump and the Wingate $5 \mathrm{~s}$ test reported as an absolute value. Perhaps it can be postulated that these two variables are the ones unrelated to physical characteristics that help explain the variance between men and women. As the correlations between these two variables were relatively low, $r=.48$ for men and $r=.34$ for women, they appear to measure different attributes. This suggests that power as tested by the vertical jump is not measuring the same factor as anaerobic power measured by the Wingate $5 \mathrm{~s}$ test. In fact, Adamson and Whitney (1971) have contended that the vertical jump is not a true measure of human power.

Studies of other fitness parameters, such as aerobic power, and muscular strength, have also noted the positive effect of reporting data relative to body weight and FFM when investigating differences between the sexes. Sparling (1980) in a meta-analysis of 13 studies comparing $\mathrm{VO}_{2}$ max between males and females found that per cent differences decreased from an absolute value difference of $56 \%$ to $38 \%$ to $15 \%$ when adjusted for body weight and FFM respectively. More recently Zwiren et al (1983), after equating groups relative to training habits, noted $\mathrm{VO}_{2}$ max changes from $44.6 \%$ for absolute values to $17.7 \%$ corrected for body weight. When adjusted to FFM the differences between males and females was reduced to $3.3 \%$ and was not significant. Wilmore (1974) noted similar changes when reporting muscular strength differences. For example, the strength of women compared with men increased from $37 \%$ to $46 \%$ to $53 \%$ for bench press and from $73 \%$ to $92 \%$ to $106 \%$ for leg press, when reporting absolute values, values relative to body weight and values relative to FFM.

In comparing the different anaerobic tests it was found that the Wingate $5 \mathrm{~s}$ anaerobic power test correlated better with the anaerobic capacity tests than with the MargariaKalamen and Lewis anaerobic power tests. Correlations between the Wingate $5 \mathrm{~s}$ test and the other two power tests were $r=.85$ and $r=.83$ for the Lewis and MargariaKalamen respectively compared to $r=.95$ for the Wingate $30 \mathrm{~s}$ test, and $r=.91$ for the Katch $40 \mathrm{~s}$ test. It is postulated that the $5 \mathrm{~s}$ data collection period of the Wingate test, which is initiated approximately 2 to $3 \mathrm{~s}$ after commencement of work, may be measuring different physiological indices of anaerobic metabolism than the other two, much shorter duration, anaerobic power tests.

This study is supportive of other studies that have investigated potential differences in fitness performance between men and women in that, when values are reported as absolutes, then significant differences exist. However, these differences are reduced when data is adjusted for body weight and further reduced when corrected for FFM. The study found no significant differences between men and women in either anaerobic power or anaerobic capacity when values were given relative to FFM.

\section{References}

Adamson, G. T. and Whitney, R. J., 1971 "Critical appraisal of jumping as a measure of human power". In Biomechanics II (pp. 208-211). University Park Press, Baltimore. 
Bar-Or, O., Dotan, R., Inbar, O., Rothstein, A., Karlsson, J. and Tesch, P., 1980 "Anaerobic capacity and muscle fibre type distribution in man". Int.J. Sports Med. 1: 82-85.

Ben Ari, E., Inbar, O., Bar-Or, O., 1978 "The aerobic capacity and maximal anaerobic power of 30-to-40-year-old men and women". In G. Book, F. Landry and W. A. Orban (Eds.). Biomechanics of sports and kinanthropometry. Proceedings of the International Congress of Physical Activity Sciences. (pp. 427-433). Quebec.

Bray, J. H. and Maxwell, S. E., 1982 "Analysing and interpreting significant MANOVA's". Rev.Ed.Res. 52: 340-367.

DeBruyn-Prevost, P. and Sturbois, X., 1984 "Physiological response of girls to aerobic and anaerobic endurance tests". J.Sports Med. 24: 149-154.

Drinkwater, B. L., 1984 "Women and exercise: physiological aspects". In R. Terjung (Ed.), Exercise and Sport Sciences Reviews (Vol. 12) (pp. 21-51). The Collamore Press, Lexington, Ma.

Fox, E. and Mathews, D., 1974. Interval Training. Conditioning for Sports and General Fitness. W. B. Saunders, Philadelphia.

Gleim, G. W., Small, C., Liederbach, J. J., Marino, M., DePasquale, E. and Nicholas, J. A., 1984 "Anaerobic power of professional ballet dancers". Med.Sci.Sports Ex. 16: 193-194.

Jackson, A. S. and Pollock, M. L., 1978 "Generalised equations for predicting body density of men". Brit.J.Nutr. 40: 497-504.

Jackson, A. S. and Pollock, M. L., 1982 "Steps toward the developoment of generalised equations for predicting body composition of adults". Can.J. Appl.Sports Sci. 7: 189-196.
Jackson, A. S., Pollock, M. L. and Ward, A., 1980 "Generalised equations for predicting body density of women". Med.Sci.Sports Ex. 12: 175-182.

Katch, V. L. and Weltman, A., 1979 "Interrelationship between anaerobic power output, anaerobic capacity and aerobic power". Ergonomics 33: 325-332.

Katch, V., Weltman, A., Martin, R. and Gray, L., 1977 "Optimal test characteristics for maximal anaerobic work on the bicycle ergometer". Res.Q.Am.Assoc. Health Phys.Educ. 48: 319-327.

Murphy, M. M., Patton, J. F. and Frederick, F. A., 1984 "A comparison of anaerobic power capacity in males and females accounting for differences in thigh volume, body weight and lean body mass". Med.Sci. Sports Ex. 16: 108.

Pate, R. R. and Kriska, A. 1984 "Physiological bases of sex difference in cardiorespiratory endurance". Sports Med. 1: 87-98.

Siri, W. E., 1961 "Body composition from fluid spaces and density". In Brozek J. and Henschel, A. (Eds.) Techniques for measuring body composition. National Academy of Sciences, Washington, D.C.

Sparling, P. R, 1980 "A meta-analysis of studies comparing maximal oxygen uptake in men and women". Res.Q.Ex.Sport 51: 542-552.

Wells, C. L. and Plowman, S. A., 1983 "Sexual differences in athletic performance: Biological or behavioural?" Physician Sports Med. 11: 52-63.

Wilmore, J. H., 1974 "Alterations in strength, body composition and anthropometric measurements consequent to a 10-week weight training program". Med.Sci.Sports 6: 133-138.

Zwiren, L. D., Cureton, K. J. and Hutchinson, P., 1983 “Comparison of circulatory responses to submaximal exercise in equally-trained men and women". Int.J.Sports Med. 4: 255-259.

\section{BOOK REVIEW}

Title: CLAYTONS ELECTROTHERAPY

Authors: $\quad$ A. Forster and N. Palastanga

Publisher: Bailliere TindallW. B. Saunders. Available from Holt Saunders Ltd., 1 St. Anne's Road, Eastbourne, East Sussex BN21 3UN

Price $£ 8.50 \quad$ ISBN 0-7020-1100-2

Claytons Electrotherapy, Theory and Practice, has been a valued textbook for many generations of student physiotherapists. It is now in its ninth edition, the first edition being in 1948.

Miss Angela Forster, MCSP, DipTP, Principal of Normanby College School of Physiotherapy, Kings College Hospital, and Mr. Nigel Palastanga, BA, MCSP, DipTP, Assistant Principal of the School of Physiotherapy, Addenbrookes Hospital, Cambridge, have undertaken a major revision of the Eighth edition which they produced in 1981.

Here is a more streamlined textbook which has much updated and new information added to most chapters. On first examination the binding seems much more secure than the previous edition.

Chapter one gives a clear introduction to physics and basic electrical equipment. Next is a valuable explanation of basic electrical components which explains mains supply house wiring, plug wiring, earthing and useful information concerning cost of electricity, electric shock and its effects and treatment. Added to chapter three is the technique of lontophoresis, Biofeedback, which is a valuable adjunct to physiotherapy, though not a treatment in its own right. Pain modulation using TNS and Interferential therapy, Pulsed Electromagnetic Energy an interesting follow-on to the very useful section on SWD. Is it the EMF itself and NOT the heat produced that influences body tissues?

Laser (Light Amplification Stimulated Emission Radiations) is the newest modality in electrotherapeutics. There is a simple and clear explanation of the types of laser available, how it is used and contra-indications.

Chapter five is much expanded and enhanced by good references. I would have welcomed emphasis on the need for accuracy in localising the site of treatment with U/S. An interesting paragraph on ozone formation has been added to the clear description of the theory and practice of using Ultraviolet Radiation.

The final two chapters cover Cold therapy and Mechanics. The chapter on mechanics is essential as an aid in the study of movement. Mechanics is a branch of applied mathematics, dealing with motion and tendencies to motion which is of considerable importance to the physiotherapist.

I strongly recommend this new edition both to students and clinicians. 